\title{
Multi-competence at the Discourse Level: A Comparison of Persuasive Essays by Chinese College and High School EFL Students
}

\author{
Yingqin Liu \\ Cameron University, 4402 SW Rolling Hills Dr. Lawton, Oklahoma 73505 U.S.A. \\ Email: yliu@cameron.edu \\ William Carney \\ Cameron University, 4402 SW Rolling Hills Dr. Lawton, Oklahoma 73505 U.S.A. \\ Email: wcarney@cameron.edu
}

\begin{abstract}
In order to explore instances of "multi-competence" (Cook, 2003) at the discourse level, a study was conducted in which two groups of student participants from a college and a high school in China, respectively, were asked to write persuasive essays in both English (L2) and Chinese (L1). The study found that the college participants exhibited greater multi-competence at the discourse level than did their high school counterparts as they were far more likely to organize both their L2 and L1 essays deductively than were the high school participants, who used more inductive strategies for $\mathrm{L1}$ writing while using deductive strategies in somewhat greater frequency in their $\mathbf{L 2}$ writing. The study suggests that the college students' greater proficiency in L2, which resulted from having received more $L 2$ instruction and $L 2$ writing practice, provides them a wider array of organizational choices in their L2 and L1 essays than those available to the high school students whose L2 proficiency was naturally lower. The study supports Kecskes' and Papp's (2003) assumption that, as $\mathrm{L} 2$ language proficiency increases, the multi-competence of $\mathrm{L} 2$ users at the conceptual level becomes stronger and more salient. The study also suggests that the relationship between $L 1$ and $L 2$ is more nuanced than the unidirectional assumption (L1 influences L2 only) still informing much ESL and EFL teaching and scholarship.
\end{abstract}

Index Terms-multi-competence, rhetoric, Chinese, EFL

\section{INTRODUCTION}

Vivian Cook (1991) first defines the concept of "multi-competence" in second language learning as "the compound state of a mind with two grammars'. However, multi-competence is now usually said to be 'the knowledge of more than one language in the same mind' (Cook, 2007). "Multi-competence thus presents a view of second language acquisition (SLA) based on the second language (L2) user as a whole person rather than on the monolingual native speaker" ("Multi-competence," 2010). In fact, multi-competence is perhaps closest to approaches that treat language as a continuously changing system (De Bot et al, 2005; Herdina \& Jessner, 2002). Since Cook's introduction of the concept of multi-competence, an increasing number of SLA scholars have explored the issue of how the first language (L1) users' knowledge of a second language (L2) actually influences their use of the L1 language. Most SLA studies on multi-competence have been focusing on L2 effects on L1 in the areas of phonology, vocabulary, syntax, and pragmatics (Pavlenko, 2000). There is, however, a scarcity of research in multi-competence regarding L2 influence on L1 at the discourse level (i.e., defined in this context as the pattern of rhetorical organization and metadiscourse of a piece of writing). Indeed, much contemporary ESL and EFL scholarship still views the relationship between L1 and L2 as unidirectional (L1 influences L2 only). Further, much scholarship in the field still treats language and writing systems as discrete entities.

Drawing insights from Cook's (2002, 2003, 2007) "multi-competence" theory, Kecskes' and Papp's (2000) "common underlying conceptual base" theory, and scholarships on contrastive rhetoric (Connor, 1996; Kaplan, 1966) and Chinese rhetoric (Becker, 1995; Matalene, 1985; Mohan and Lo, 1985; You, 2005), the present study seeks to explore any instances of multi-competence regarding L2 influence on L1 persuasive essays at the discourse level through comparing and contrasting some rhetorical organizational features found in English (L2) and Chinese (L1) persuasive essays written by Chinese EFL college and high school students. We will first overview the theoretical foundations guiding the present study. Next, we will introduce our research questions, methods, findings, and discussion. Finally, we will attempt to draw conclusions and discuss some implications from the study.

\section{THEORETICAL FRAMEWORKS}




\section{Cook's "Multi-competence” Model}

Previously, as Zareva (2010) suggests, the notion of multi-competence provides a rather different way of viewing bilingual speakers and writers. While some SLA researchers have focused on treating deviation from standard L2 writing as a result of "interference" from L1 (Coppetiers, 1987; Weinrich, 1953), scholars such as Cook (2007) defines the concept of multi-competence as the knowledge of two or more languages in one mind.

Cook $(2002,2003)$ classifies the relationship between first and second languages in the mind of a bilingual user into three models: the Separation model, the Interconnection model, and the Integration model. See Figure 1 below for a visual representation of these models.

separation

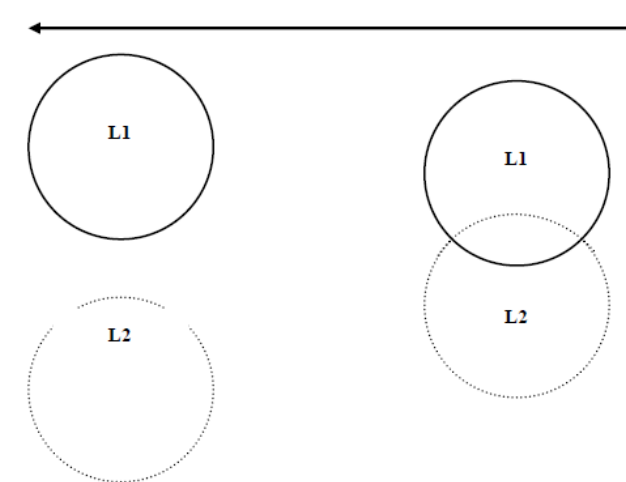

integration

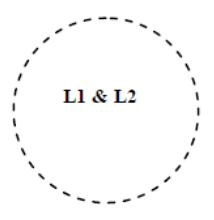

Figure 1. The integration continuum of possible relationships in multi-competence (Cook, 2003). Reproduced with Author's Permission

The separation model, which forms much of the early SLA teaching methodologies, attempts to avoid any reference to the first language and discourages its use in the L2 classroom in an attempt to help students build up a new language system with no links to the L1. This model sees no point to discussing the effects of the L2 on the L1, as they are assumed not to exist (Cook, 2003). This rather traditional model often still informs ESL (English as a Second Language) pedagogy.

The integration model, on the other hand, employs an idea that the two languages form a single system. Thus, L2 users are able to choose which language to use in a given context just as a monolingual speaker or user can choose which style or register to adopt in a particular situation.

The third model, the interconnection model, acknowledges that there are many different degrees and types of interconnections between L1 and L2 in an L2 user's mind. Cook (2003) states that the interconnections are displayed in two different directions. First, the development and use of the L2 is affected by the already-existing L1 as Odlin (1989) demonstrates. Thus, there is, in terms of language transfer, an inhibition or facilitation effect of the first language on the second in the process of second language acquisition (Isurin, 2000). Second, it seems that "studies of 'transfer' or "influence"" have assumed an interconnection model by focusing on the L2 element in multi-competence taking advantage of the first language. Because of the existence of these two interconnections, Cook (2003) suggests that there may be legitimate L2 effects on L1 in an SLA context.

The present study is informed by this interconnection model (Cook, 2003), which posits a continually changing relationship between the L1 and all subsequently acquired language systems, which are themselves in a state of development. This model has provided one of the theoretical bases for the present study to interpret and explain the research data in the discussion section of the study.

Kecskes' and Papp's “Common Underlying Conceptual Base” Theory

While some SLA scholars examine L2 effects on L1 in an ESL context, Kecskes and Papp study the effects of L2 on L1 in an environment where the main source of foreign language (FL) is classroom instruction, and the target language culture is not directly present. They argue that both bilingual development and intensive foreign language learning may lead to the emergence of a Common Underlying Conceptual Base (CUCB) that is responsible for the operation of two language channels. They define the CUCB as the basis and originator of all bilingual or multilingual linguistic actions, a 'container' that includes everything but the language system itself (Kecskes \& Papp, 2003). They contend that, "[it] is in the CUCB that the socio-cultural heritage and previous knowledge of the learner are confronted with the new information entering the CUCB through both language channels, and the real world knowledge mixes with academic knowledge and develops into something that is frequently referred to as 'socio-cultural background knowledge"' (Kecskes \& Papp, 2000 p. 104).

However, elsewhere they insist that the development of a Common Underlying Conceptual Base may be dependent on L2 users' L2 proficiency, which has to reach a certain hypothetical threshold (Kecskes \& Papp, 2003). In order for a Dual Language System (DLS) to develop, the conceptual structure needs to change from an L1-Conceptual Base into a Common Underlying Conceptual Base. The more proficient the L2 user becomes in the L2 and the more firmly the CUCB is established in the mind, the greater the likelihood that positive transfer may occur. Positive transfer, of course, is the transfer of any kind of movement or influence of concepts, knowledge, skills or linguistic elements (structure, 
forms), in either direction, between the L1 and the subsequent language. Kecskes and Papp (2000) maintain that this positive transfer is neither structural nor lexical but pragmatic. Thus, the L2-L1 effect in a foreign language environment is conceptual rather than purely linguistic, and it affects the use of L1 as a whole (Kecskes \& Papp, 2003). This being said, Kecskes and Papp seem to suggest that L2 effects on L1 in an environment such as English as a foreign language may well operate at the rhetorical or discourse level as long as a user's L2 proficiency has reached a certain hypothetical threshold.

The present study not only draws insight from but also lends some support to this CUCB model as the data here indicate that both the length of exposure to and depth of acquisition of L2 contribute to the development of the CUCB, something we will discuss later in this article. Indeed, we suggest that the results of the present study lend support to the existence of a CCUB and that Kecske's and Papp's model was essential to our research.

Perspectives on Contrastive Rhetoric and Chinese Rhetoric

Contrastive rhetoric is an area of research in second language acquisition that concerns itself with problems in composition encountered by second language writers (Connor, 1996). By referring L2 writers to the use of rhetorical strategies of the first language, contrastive rhetoric maintains that language and writing are cultural phenomena, that different cultures have different rhetorical tendencies, and that the linguistic patterns and rhetorical conventions of the first language often transfer to writing in ESL and thus cause interference (Connor, 1996). Since the inception of contrastive rhetoric, many researchers have joined the ongoing discussion regarding comparisons between the organizational patterns of Chinese rhetoric and English rhetoric. So far, three distinct perspectives on the organizational patterns of Chinese rhetoric have emerged.

The first perspective views Chinese writing as essentially indirect. Kaplan (1966) describes Chinese ESL students' paragraph development as "turning and turning in a widening gyre. The circles or gyres turn around the subject and show it from a variety of tangential views, but the subject is never looked at directly" (p. 10). Matalene (1985) supports Kaplan's hypothesis and shows in sample essays written by her Chinese EFL students that the claims (in persuasive writing) are often delayed. Their research, however, has been criticized for their methodological flaws such as being overgeneralization based on a small research sample (Benda, 2006; Connor, 2002).

The second perspective claims that Chinese writing is as direct as the typical Western writing style. Mohan and Lo (1985) argue that both classical and modern Chinese styles taught at schools today favor a direct rather than an indirect expressive mode. They compare ESL writing instruction in Hong Kong and British Columbia, and conclude that the "inappropriate" (meaning different from English organizational structure) organizational structure in ESL texts may be nothing more than a result of developmental factors. Teachers in Hong Kong tend to emphasize sentence correctness and pay less attention to organization in writing; thus, competence in rhetorical organization develops later for these students. Zhang (1997) also rejects the view that Chinese writing organization is indirect as his subjects wrote with more "traditional" Western rhetorical features. Additionally, Kirkpatrick (1997) argues that contemporary Chinese textbooks on composition no longer teach students to use the "eight-legged" essay nor "qi-cheng- zhuan -he" text structure, which involves an indirect approach to the topic and an unexpected shifting of topics. Instead, he explains that the textbooks teach students to take a direct approach to the opening and closing of a text, clear arrangement of idea, and the linear structure of both deductive and inductive reasoning. He claims that the "English writing of such students will be similarly influenced by Western rather than by traditional Chinese styles" (Kirkpatrick, 1997, p. 255). Similarly, You (2005) also argues that Mainland Chinese students have long been taught to write Chinese composition in "AngloAmerican" rhetorical style instead of the "eight legged" essay style, so they are more influenced by western writing style.

While Kirkpatrick and You emphasize that modern Chinese students are, indeed, taught to use a deductive approach in writing, they seem to underestimate the impact of Chinese cultural values and literary tradition on Chinese EFL students writing, which in many cases can lead to students' preferring an indirect approach (Fei \& Han, 2007; Liu, 1996; Liu, 2009). As Liu (2008) points out that "[t]o some extent he [Kirkpatrick] ignores the fact that internal construct of Chinese rhetoric may retain solidity whereas its external patterns are changing over times" (p.4). Wu (2009) also states, "his [You's] optimistic narrative overlooks the debate between two powerful oppositional nativists who adhered to Chinese literacy tradition" (p.149). According to Malcolm and Pan (1989), this Chinese literary tradition which advocates indirect writing as superior to a more straightforward way of expression has greatly influenced how Chinese students approach their persuasive essays. For example, Fei's and Han's ( 2007) research indicates that many writing instructors and students nowadays still hold the famous Chinese proverb, Hua long dian jing (paint the dragon and then draw the eyes), which teaches that important things always come last in people's writing. Gu (2003) argues that Hanxu ("be suggestive or reserved"), another much appreciated Chinese literary tradition (Liu, 1996), still exerts an impact on Chinese writing. As Fung (1976), the renowned historian of Chinese philosophy, puts it, "Suggestiveness, no articulateness, is the ideal of all Chinese art, whether it be poetry, painting, or anything else" (p. 12). Thus, suggestiveness (hanxu) is an essential part of Chinese subtle rhetoric and has been considered by Chinese people as the height of culture and the mark of good breeding (Snively, 1999). The influence of this Chinese subtle rhetoric of hanxu on contemporary Chinese writing instruction and Chinese students' writing is profound. For example, it makes many writing instructors emphasize the elegant and indirect approach in Chinese essay writing by teaching their students to 
place their theses statements in multiple places in their essay to achieve some rhetorical effects such as hanxu (Fei \& Han, 2007; Liu, 2009).

The third perspective states that Chinese writing can be regarded as a combination of directness and indirectness. Wang (1992) argues that the ESL data used by some scholars might not accurately reflect the rhetorical patterns and conventions of the source language. Thus, he studies Chinese texts from 20 Chinese journal articles and English texts from 20 English journal articles as the data corpus for his analysis. He finds that the methods for paragraph structure were similar in Chinese and English writing. There are, however, differences in how the arguments are made. English writing tends to use a deductive method while the Chinese writing displays deductive, inductive and a combination of the two in the writing organization (Wang, 1992). He attributes this phenomenon to "the interaction between Chinese rhetorical tradition on the one hand and modern English influence on the other" (Wang, 1992, p. 133). Also, Becker's study (1995) of ESL Chinese students' English essays reveals that Chinese students' English writing can be described as a complex cluster of rhetorical organizations: Some students introduce the topic at the beginning of the essays, while others, instead of discussing the thesis directly, present examples first and deal with the thesis in the conclusion. Zhang (2011) also concludes in her literature review on Chinese and English contrastive research that there is no agreement on the studies of Chinese-English rhetoric patterns, but the overall message is that there are differences; after all, Chinese rhetoric is diverse as it includes the traditional rhetoric heritage and the influence of western rhetoric. Additionally, Yang and Cahill (2008) studied 100 expository essays by 50 American university students in English and 50 Chinese university students in Chinese. They find "that Chinese students, like their U.S. counterparts, also used directness in text and paragraph, but generally U.S. students tend to be significantly more direct than Chinese students" (Yang \& Cahill, 2008 p.113), which implies that Chinese students incorporate both direct and indirect approaches in their Chinese essays.

While all the three perspectives have contributed to the ongoing discussion on Chinese Rhetoric for ESL purposes, we, take the stance of the third perspective: Chinese rhetoric uses a combination of deductive and inductive organization in essay writing. Additionally, we also argue for the assumption that Chinese rhetoric shows a preference for an inductive approach because of the influence of Chinese cultural values and literary tradition (Fung, 1976; Gu, 2003; Liu, 1996; Snively, 1999), which means that people may see more inductive approach in Chinese students' L1 (Chinese) writing.

In short, our support to the assumption that Chinese writers may show a preference for an inductive/ indirect approach in their Chinese writing due to the influence of Chinese cultural values and literary tradition serves as a premise for us to interpret and explain the research data on the Chinese college and high EFL students' L2 and L1 persuasive essays from the perspectives of multi-competence and the likely existence of a Common Underlying Conceptual Base at the discourse level.

\section{RESEARCH QUESTIONS}

In order to explore any instances of multi-competence regarding L2 effects on L1 persuasive writing at the discourse level, we asked the following research questions:

(1) Do Chinese EFL high school students use the similar or different rhetorical organization patterns in their persuasive essays in Chinese (L1) and English (L2)?

(2) Do Chinese EFL college students use the similar or different rhetorical organization patterns in their persuasive essays in Chinese (L1) and English (L2)?

(3) What kind of metadiscourse features do the Chinese college and high school EFL students display in their English (L2) persuasive essays?

(4) What kind of metadiscourse features do the Chinese college and high school EFL students display in their Chinese (L1) persuasive essays?

\section{RESEARCH METHOD}

\section{Participants}

During June 2006, two groups of Chinese EFL student participants were recruited. The first group was composed of 50 students at a northwest International Languages Studies University, China, majoring in English and in the second semester of their junior year. The second group was composed of 50 students from a northwest High School, China, and at the end of the tenth grade (six year in primary school and three years at junior high, and one year in high school). When the study was conducted, the students at the university had been studying English as a foreign language for about nine years, including six years in high school (where English learning is characterized as focusing on basic grammar, sentence structure, and simple paragraph reading and writing) and three years in the university (where English was their major, and English learning was very intensive, focusing on listening, speaking, reading and writing in both paragraph and essay). On the other hand, the students at the High School only had an average of four years of formal English learning experiences. In addition, most of the participants from the university had passed the National Band IV English Test for English majors (a requirement for the bachelor's degree in English major, which is different from National Band IV College English Test for non-English major in that the test is much more demanding in reading and writing 
skills) and had received two years' systematic English writing instruction and practice, in which they learned one semester's English paragraph writing and one semester's English essay writing during the sophomore and one year's professional writing during their the college junior year. All participants, both at the college and high school level, were asked to compose one persuasive essay in Chinese and one in English. Both the Chinese and English essays were written to the same prompt. Additional information regarding the prompts will be found in the appendices to this paper.

Data collection

The writing tasks were administered by the student participants' English teachers during their class time. In an attempt to reduce the possibility of the participants' translating their Chinese essays into English for the writing tasks, we required the English teachers to have the participants write the English persuasive essay first. After an interval of one week, the participants were asked to write a Chinese persuasive essay. Please see the essay prompts in Appendix A.

Data analysis

According to Huckin (2004), the units of analysis or text features to be identified for analysis must be those that emerge logically from the research question. So the text features analyzed in the present study are:

- the placement of the thesis statement in both persuasive essays in L2 and L1,

- the metadiscourse features (e.g., transition words or phrases) displayed in both persuasive essays in L2 and L1, and,

- the general organization patterns (e.g. inductive or deductive) of both persuasive essays in L2 and L1.

In order to avoid misrepresentation in the data collection of the present study and to increase the reliability of coding or analysis process, as MacNealey (1999) recommends, we used one second coder for analyzing the English persuasive essay data. This co-coder is a native English speaker, and he had two years' ESL teaching experience, and holds BA degrees in English and Psychology. Thus, the co-coder was not only familiar with English academic writing but also understood the ESL/EFL student s' writing well. We also used one second coder for analyzing the Chinese persuasive essay data. The Chinese co-coder is a native Chinese speaker, who has a doctoral degree in architecture. She received her MA in architecture in China. Therefore, the Chinese co-coder was proficient in her Chinese academic writing.

With both co-coders, we separately sorted $50 \%$ of the data into three predetermined coding categories as listed above, and then we and the co-coders met to discuss the results of coding. During this process, the respective sorting/coding was compared for inter-rater reliability.

Findings

To answer the first two research questions, we compared the rhetorical organization patterns of both groups of students' L2 (English) essays with those of their L1 (Chinese) essays. Rhetorical organization (e.g., deductive or inductive) is defined as where these students placed their thesis statements. The results of the comparison are shown in Table 1 and Table 2. Please note the "keys" below Table 1 for operational definitions of each category and key term.

TABLE 1

HIGH SCHOOL STUDENTS N=50 (CHINESE) N=50 (ENGLISH)

\begin{tabular}{|l|l|l|}
\hline Organization & L2 (English) Essay & L1 (Chinese) Essay \\
\hline Deductive & 34 & 13 \\
\hline Inductive & 14 & 23 \\
\hline None of the above & 2 & 14 \\
\hline
\end{tabular}

Keys

- A thesis statement is the basic stand one takes, the opinion one expresses, the point one makes about one's limited subject; it is one's controlling idea, tying together and giving direction to all other separate elements in ones' paper (Skwire, 1979).

- Deductive- Thesis presented at beginning of essay, followed by supporting details and conclusion.

- Inductive-Examples and details presented first, thesis placed in final paragraph.

- None of the above - including essays presenting implied thesis statement, which means that examples and details supporting one side of argument are presented, but no explicit thesis neither at the beginning nor in the end; also including essays that were off-task writing.

Table 1 shows some major differences as to how the high school students organized their L2 and L1 persuasive essays, respectively. Fully $68 \%$ of the students organized their L2 (English) essay deductively while only $26 \%$ used the same organization in their L1 (Chinese) essays. However, 46\% of the students organized the L1 (Chinese) essays inductively, and $28 \%$ of them showed no clear deductive or inductive organization, but only gave some hints such as related examples and evidence about the topic to let the reader infer the thesis of the essay for himself or herself.

TABLE 2

COLLEGE STUDENTS N=50 (CHINESE) N=50 (ENGLISH)

\begin{tabular}{|l|l|l|}
\hline Organization & L2 (English) Essay & L1 (Chinese) Essay \\
\hline Deductive & 40 & 46 \\
\hline Inductive & 10 & 4 \\
\hline None of the above & -- & -- \\
\hline
\end{tabular}

Table 2 indicates major similarities between how the college students organized their L2 and L1 persuasive essays, respectively. About $90 \%$ of the students organized their L2 (English) essay deductively while, similarly, about $92 \%$ of 
these students also used the deductive organization for their L1 essays. However, compared with their L1 essays, the college students used more inductive organization in the L2 essays.

To answer research questions three and four, we compared and contrasted the metadiscourse features that displayed in the L2 (English) and L1 (Chinese) persuasive essays written by the Chinese EFL college students and of those written by the Chinese EFL high school students. Krause and O'Brien (1999) define metadiscourse as the use of the linguistic markers comprising words and phrases that do not add propositional material but help readers organize, classify, interpret, evaluate, and react to such material such as connectives like however or in other words. Hyland (2003) further explains that those linguistic markers are also called "signposts" to help readers navigate through the writer's arguments and serve to explicitly organize the text and comment on it by using sequencing points (first, next, last), connecting ideas ( however, therefore), and showing what the writer is doing (to summarize, for example) and so forth. The results of the comparison are shown in Table 3 below.

TABLE 3

$\mathrm{N}=50$ (ENGLISH) $\mathrm{N}=50$ (CHINESE)

$\mathrm{CS}=$ COLLEGE STUDENTS HSS $=$ HIGH SCHOOL STUDENTS

\begin{tabular}{|c|c|c|c|c|c|}
\hline Transitions / Signposts & $\begin{array}{l}\text { Location in essay } \\
\text { draft }\end{array}$ & $\begin{array}{l}\text { L2 } \\
\text { CS (English) }\end{array}$ & $\begin{array}{l}\text { L1 } \\
\text { CS (Chinese) }\end{array}$ & $\begin{array}{l}\text { L2 } \\
\text { HSS (English) }\end{array}$ & $\begin{array}{l}\text { L1 } \\
\text { HSS (Chinese) }\end{array}$ \\
\hline First, first of all (首先) & $\begin{array}{l}\text { Initial position of } \\
2^{\text {nd }} \text { paragraph }\end{array}$ & 26 & 19 & 4 & 3 \\
\hline $\begin{array}{l}\text { Second, next, furthermore, } \\
\text { however (其次) (然而) }\end{array}$ & $\begin{array}{l}\text { Initial position } \\
\text { of } 3^{\text {rd }} \text { paragraph }\end{array}$ & 26 & 19 & 4 & 3 \\
\hline $\begin{array}{l}\text { Third, additionally, moreover, } \\
\text { (第三) (再者) }\end{array}$ & $\begin{array}{l}\text { Initial position } \\
\text { of } 4^{\text {th }} \text { paragraph }\end{array}$ & 26 & 19 & 4 & 3 \\
\hline $\begin{array}{l}\text { Finally, after all, in fact (最后) } \\
\text { (事实上) }\end{array}$ & $\begin{array}{l}\text { Initial position } \\
\text { of penultimate } \\
\text { paragraph }\end{array}$ & 26 & 19 & 4 & 3 \\
\hline $\begin{array}{l}\text { To sum up, in a word, on the } \\
\text { whole, so, (总之) (所以) }\end{array}$ & $\begin{array}{l}\text { Initial position } \\
\text { of final paragraph }\end{array}$ & 28 & 38 & 28 & 29 \\
\hline
\end{tabular}

Table 3 indicates that, in order to signal the movement of ideas and to show the logical connection between the paragraphs, $52 \%$ of the college students used the transitions/signposts at the initial position of each paragraph in their L2 essays, and $38 \%$ of them also used these words in their L1 essays. In contrast, only $8 \%$ of the high school students exhibited these metadiscourse features in their L2 essays, and $6 \%$ of them displayed these features in their L1 essays.

\section{DISCUSSION}

The findings for the first and second research questions (see Table 1 and Table 2) reveal that the L1 (Chinese) persuasive essays of the high school EFL students are more inductive and not much influenced by their L2 (English) persuasive essays which are more deductive at the discourse level while L1 persuasive essays of the college participants share the same deductive approach as their L2 essays. That is to say that multi-competence regarding L2 influence on L1 persuasive essays at the discourse level for the college participants seem stronger than that of the high school participants. This finding supports the assumption that L2 language proficiency is one of the factors shaping the L2-L1 relation after the hypothetical threshold is reached (Kecskes \& Papp, 2003) and that, as language proficiency increases, the effects of multi-competence at the conceptual level becomes stronger and more salient (as cited in Zareva, 2010).

Although "hypothetical threshold" is a somewhat undefined term, based on the finding here, we suggest that this framework might be largely dependent on proficiency and factors such as language and intellectual development. Clearly, college English learning for English majors in China is far more intensive than that provided in high school, and the college participants in the present study had received five additional years of English (and other) instruction, especially two years' systematic English writing instruction and practice. Length of study in L2 seems important, but depth and breadth of L2 learning (vocabulary, grammar, syntax, rhetoric, and literature) such as the college English study for the English majors in present study might be what led to any sort of significant L2 impact on L1 in the present study. Su (2001), for example, also finds that advanced Chinese learners of English use the same writing strategies in both languages, and their Chinese linguistic processes are influenced by English, although this is not true of lower-level learners in her study.

In fact, English rhetorical influence on Chinese rhetoric through the channel of higher (and formal) education has been studied by Chinese sociolinguists from the perspective of the relevance of cultural identity to language learning. Based on her case study of English majors that explores the relationship between cultural identity and language learning, Gao (2007) describes the impact of English learning on her subject, Aiwen, "who was fond of reading Chinese literature and writing Chinese prose before entering college" as follows,

After several years of strict training in the "linear" style of English essay writing, she was shocked to find her own prosaic Chinese writing style changed toward the linear direction: "My god, how could that be written by myself?!" ... "I feel a bit sorry.... I enjoyed the leisurely loose and roundabout style. Now I am afraid I can never find that look of mine anymore... the style of a free man of letters." (Gao, 2007, p. 102) 
Although Gao interprets this English rhetorical impact on Chinese rhetoric as a change in her college subject's cultural identity in terms of communication style from the perspective of sociolinguistics, we suggest that this phenomenon be also understood as evidence that the higher English proficiency of the college student leads to her unconscious use of English organization in her Chinese writing. Thus, both the present study and the research of Gao seem to support Kecskes' and Papp's (2000) assumption about L2 effects on L1 in an environment such as learning English as a foreign language may well operate at the rhetorical or discourse level as long as L2 users' L2 proficiency has reached a certain hypothetical threshold.

In addition, Hirose (2003), studying the relationship between Japanese students' first language and second language writing in terms of rhetorical organization, compares L1 (Japanese) and L2 (English) organizational patterns in the argumentative writing of Japanese EFL college student-writers. Hirose's research also reveals that a majority of Japanese college students use deductive type organizational patterns in both L1 and L2, in spite of the popular assumption that "one feature commonly identified by research as a characteristic of Japanese writing is "induction"" (Kubota, 1998 p. 478). Hirose maintains that L1 argumentative writing experience may not be a necessary condition for L2 organizational ability to develop because the Japanese college students in her study do not receive formal argumentative writing training in their L1. She concludes that L2 writing instruction and experience may be transferable to L1 writing. In other words, Hirose seems to be suggesting that L2 (English) writing influence on L1 writing (Japanese) at the discourse level is possible. So, both our findings in present study and Hirose's research provide a good degree of concordance to Cook's $(2002,2003,2007)$ assumption that there may be legitimate L2 effects on L1 in an SLA context, named as multi-competence, but we also suggest that we identify this displayed L2 effect of rhetorical patterns on L1 as the instance of multi-competence at discourse level for L2 users.

Another instance of multi-competence at the discourse level for the two groups of participants due to the different L2 proficiency revealed by the present study seems to be the differences in the use of metadiscourse features between the Chinese college and high school EFL students (see Table 3). The higher incidence of transitions in the L2 and L1 writing of college EFL students may indicate here again that this phenomenon might be an L2 influence on L1. For high school students, on the other hand, the low incidence of these metadiscourse features in L2 essays seems to suggest that using transitions to signal the logical connection between the paragraphs in their L2 essays be something that creates great difficulty for them because of their lower L2 proficiency in writing compared with the college students. So there is no apparent L2 effect on L1 regarding the metadiscourse features in their persuasive essays. On the contrary, they use L1 essay strategies in their L2 essay to indicate the connections between the paragraphs. For example, the new paragraph may start as a comparison, a contrast, an addition, or an explanation to the previous paragraph. The readers, thus, are left to assume the transition or assess the relationship between the ideas in the paragraphs themselves. To illustrate this, please see one of the high school EFL participants' original L2 essays in Appendix B.

This finding that the high school EFL students use L1 metadiscourse strategies in L2 essay (due to their low L2 proficiency) seems to echo Hinds' (1987) "writer-responsible" and "reader-responsible" perspective. Hinds suggests that English is writer-responsible writing because it is the writer's task to provide appropriate transition statements when moving from one idea to the next and to regularly place signals in the text, so the reader can see how the writer intends the text to hold together (as cited in Hyland, 2003). However, Hinds believes that Japanese and Chinese are reader -responsible writing because it is the reader's responsibility for effective communication, which means that the reader is expected to infer meaning from the texts he/she is reading; as a result, the transitional statements or words in the writing may be absent. Thus, the reader has to figure out for himself or herself on how one part of an essay is related to the whole essay. As Chien (2007) further elaborates, "explicit signals are not necessary; the writer shows respect for the reader's intelligence to make inferences" (p.138).

\section{CONCLUSION AND IMPLICATIONS}

There are, of course, some limitations to the present study that warrant caution in making generalizations concerning the results. For one thing, the prompt itself may have provided clues that the writer was to compose an argumentative essay, and, thus, a deductive strategy would more likely be chosen. For another, no information was provided with the subjects, concerning what audience they might write to, which might have some impact on the organizational patterns of the English (L2) and Chinese (L1) essays. Future research might address these concerns.

The present study, however, does seem to provide some evidence for the existence of multi-competence regarding L2 influences on L1 at the discourse level (referring to rhetorical organization and metadiscourse features). The study also supports Kecskes' and Papp's (2003) assumption that, as L2 language proficiency increases, multi-competence of L2 users at the conceptual level become stronger and more salient. As Choong (2006) states, multi-competent language users can do things that no monolingual person can, and that the knowledge of the L2 not only influences L2 users' knowledge of the L1, but also enhances other perceptions and abilities as well. In present study, this knowledge of L2 and the practice of using L2 rhetorical approach seem to enhance the Chinese college L2 users' abilities in L1 writing. In other words, the multi-competence of the college participants at the discourse level seems to provide them a greater variety of rhetorical choices or features from which they can choose, such as the fact that the college participants can use direct approach smoothly in both their L2 and L1 essays and that college participants appear more flexible and willing to use transitions to indicate the movement of the ideas between the paragraphs in both their L2 and L1 essays. 
We can draw some implications for EFL teaching from the present study. Since the multilingual students inevitably bring their cultural values, discourse, and rhetoric to L2 writing classroom, writing teachers, who can draw insights from the theory and practice of multi-competence of L2 users or of the multilingual students, should be encouraged to treat the these L2 or multilingual users as "resourceful writers" (Liu \& You, 2008 p. 155). Just as Canagarajah (2002) maintains, linguistic and cultural characteristics that multilingual students display should be valued as their "resources" to enrich the academic discourse community and as representation of their unique voices and identities. Pavlenko (2003) goes somewhat further than this assertion. For her, the idea of multi-competence suggests a need for critical reflection with the ESL and EFL communities. Too often, the teaching of L2 English becomes a rather rigid ideology or, at least, one half of a rather false L1 / L2 dichotomy. Li and Girvan (2004) suggest as well that, by allowing the notion of multicompetence to inform EFL and ESL teaching, students are exposed to a more authentic view of the fluidity of language and culture. By recognizing and, indeed, embracing multi-competence, teachers can help L2 or multilingual writers better understand L2 writing conventions while promoting their L1 writing development and, most important, allowing them to draw the most appropriate rhetorical "tools" from all that they possess. The multilingual writer with the developed multi-competence in "multi-rhetorics" has resources beyond those available to even some of the more talented monolingual writers, and it is these resources that teachers of ESL/EFL writing should nurture and develop in their writing classrooms.

\section{APPENDIX A PROMPTS FOR PERSUASIVE ESSAYS IN ENGLISH}

Instructions: Among the two essay prompts given below, please chose ONE of them to write an argumentative essay of about 400 words. Be sure you will establish a clear thesis statement for your essay. You will have 50 minutes to write your essay. Please write as LEGIBLY as possible.

1. Some people think that family is the most important influence on young adults. Other people think that friends are the most important influence on young adults. Which do you think is the most important influence?

2. Some university students want to live in a room alone. Others prefer having roommates. Which do you like better-- living alone or living with roommates?

\section{Prompts for Persuasive Essays in Chinese (Translations of the English version)}

作文题目

1. 一些人认为生长在兄弟姐妹多的家庭比独生子女家庭对孩子成长更有利; 另外一些人持相反意见。

以此为题, 请用汉语写一篇 500 字左右的文章, 阐述你对此问题的看法。

2. 一些大学生 愿意 住在 集体 宿舍; 另外一些大学生 则 喜欢独自居住。你最喜欢 哪种居住方式?

以此为题, 请用汉语写一篇 500 字左右的文章, 阐述你对此问题的看法.

\section{APPENDIX B ADVANTAGES OF LIVING TOGETHER}

I think that living with roommates is better than living alone. You may not agree with me. Maybe you think it's not convenient to live with roommates. For example, they may know your secrets. You may think it's relaxed to live alone. But I insist on my opinion.

We will grow up one day. We must step into society work hard and face sorts of challenges. We have to do teamwork. So we must learn how to communicate with others from now on. To live with roommates is a good way to execrise this skill.

We live in the world, we need friends. When you feel sad, your roommates can console you. You can be good friends. Room is also a small family. You and your roommates are family members. When you think like this way, you don't miss your real family.

When you regard your room as your family, you car run it with flowers and beautiful things, you may appreciate them. You make the room full of happiness and pleasure. Room is a strong bridge of friendship between you and your roommates.

\section{REFERENCES}

[1] Becker, Ruth R. (1995). The second language writing of Chinese ESL students: Transfer and writing development. Unpublished doctoral dissertation. University of Illinois, Champaign-Urbana.

[2] Benda, Jonathan P. (2006). Qualitative studies in contrastive rhetoric: An analysis of composition research. Retrieved August 6, 2011, from Tunghai University English Department Website: http://web.thu.edu.tw/benda/www.

[3] Canagarajah, A.Suresh. (2002). Critical academic writing and multilingual students. Ann Arbor, MI: University of Michigan Press.

[4] Chien, Shihchieh. (2007). The role of Chinese EFL learners' rhetorical strategy use in relation to their Achievement in English writing. English Teaching: Practice and Critique, 6(1), 132-150.

[5] Choong, K. Philip. (2006). Multicompetence and second language teaching. Working Papers in TESOL \& Applied Linguistics, $16(1), 1-3$.

[6] Connor, Ulla. (1996). Contractive rhetoric: Cross-culture aspects of second- language writing. New York: Cambridge University Press. 
[7] Connor, Ulla. (2002). New directions in contrastive rhetoric. TESOL Quarterly, 36, 493-510.

[8] Cook, Vivian. (1991). The poverty-of-the-stimulus argument and multi-competence. Second Language Research, 7 (2), $103-$ 117.

[9] Cook, Vivian. (2002). Background to the L2 user. In Vivian Cook (ed.), Portrait of the L2 user (pp.1-18). Clevedon, UK: Multilingual Matters.

[10] Cook, Vivian. (2003). Introduction: the changing L1 in the L2 user's mind. In Vivian Cook (ed.), Effects of the second language on the first (pp. 1-18). New York: Multilingual Matters.

[11] Cook, Vivian. (2007). Multi-competence: black-hole or worm-hole for second language acquisition research. In Z. Han (ed.) Understanding second language process (pp. 16-26). Clevedon: Multilingual Matters.

[12] Coppetiers, Rene. (1987). Competence differences between native and near-native speakers. Language, 63(3), 544-573.

[13] Debot, Kees, Lowie, Wander \& Verspoor, Marjolijn (2005). Second language acquisition: An advanced resource book. New York: Routledge.

[14] Fei, Xi \& Han, Guang. (2007). Cultural impacts on indirectness in English writings of Chinese EFL learners. Intercultural Communication Studies. Special Issue, 176-183.

[15] Fung, Yu-Lan. (1976). A short history of Chinese philosophy (Derek Bodde, trans.) New York: Free Press (Original Work published 1948).

[16] Gao, Yihong. (2007). The relevance of cultural identity to language learning research in the Chinese context." Intercultural Communication Studies, XVI(1), 100-112.

[17] Gu, Mingdong. (2003). Aesthetic suggestiveness in Chinese thought: A symphony of metaphysics and aesthetics. Philosophy East and West, 53(4), 490-513.

[18] Herdina, Philip \& Jessner, Ulrike. (2002). A dynamic model of multilingualism: Changing the psycholinguistic perspective. New York: Multilingual Matters.

[19] Hinds, John. (1987). Reader versus writer responsibility: A new typology. In Ulla Connor \& Robert B. Kaplan (eds), Writing across languages: Analysis of L2 text (pp. 141-52). Massachusetts: Addison- Wesley Publishing Company.

[20] Hirose, Keiko. (2003). Comparing L1 and L2 organizational patterns in the argumentative writing of Japanese EFL Students. Journal of Second Language Writing, 12, 181-209.

[21] Huckin, Thomas. (2004). Content analysis: What texts talk about. In Charles Bazerman \& Paul Prior (eds.), What writing does and how it does it (pp.13-32). Mahwah, NJ: Lawrence Erlbaum Associates.

[22] Hyland, Ken. (2003). Second language writing. Cambridge: Cambridge University Press.

[23] Isurin, Ludmila. (2000). Deserted island or a child's first language forgetting. Bilingualism, 3, 151-166.

[24] Kaplan, Robert. B. (1966). Cultural thought patterns in intercultural education. Language Learning, 16, 1-20.

[25] Kecskes, Istvan \& Papp, Tunde. (2000). Foreign language and mother tongue. Mahwah, NJ: Lawrence Erlbaum Associates.

[26] Kecskes, Istvan \& Papp, Tunde. (2003). How to demonstrate the conceptual effect of L2 on L1? methods and techniques. In Vivian Cook (ed.), Effects of the second language on the first (pp. 234-247). New York: Multilingual Matters

[27] Kirkpatrick, Andy. (1997). Traditional Chinese text structures and their influence on the writing in Chinese and English of contemporary Mainland Chinese students. Journal of Second Language Writing 6, 223-44.

[28] Kubota, Ryuko. (1998). An interview of Japanese and English L1 essay organization: Differences and similarities. The Canadian Modern Language Review, 54, 475-507.

[29] Krause, Kerri-Lee \& O’Brien, Dan. (1999). A sociolinguistic study of the argumentative writing of Chinese students. Education Journal, 27 (2), 43-64

[30] Li, Xueumi, \& Girvan, Anita. (2004). The "third place": Investigating an ESL classroom interculture. TESL Canada Journal, $22(1), 1-15$

[31] Liu, Jianxin. (2008). The generic and rhetorical structures of expositions in English by Chinese ethnic minorities: A perspective from intracultural contrastive rhetoric. Language and Intercultural Communication, 8(1), 2-13.

[32] Liu, Yameng. (1996). To capture the essence of Chinese rhetoric: An anatomy of a paradigm in comparative rhetoric. Rhetorical Review, 14, 318-355.

[33] Liu,Yichun \& You, Xiaoye. (2008). Negotiating into academic discourses: Taiwanese and U.S. college students in research writing. International Journal of English Studies, 8(2), 152-172.

[34] Liu, Yingqin. (2009). The impact of cultural factors on Chinese and American college students' rhetorical choices in argumentative discourse: A contrastive study. Intercultural Communication Studies, 18, 128-141.

[35] MacNealy, Mary Sue. (1999). Strategies for research in writing. Boston: Allyn and Bacon.

[36] Malcolm, Lin \& Pan. Hongjio. (1989). Argumentation patterns in contemporary Chinese: Implications for English teaching. In Verner Brickley (ed.), Language teaching and learning styles within and across cultures. (pp.321-333) Hong Kong: Hong Kong Education Department Publications.

[37] Matalene, Carolyn. (1985). Contrastive rhetoric: An American writing teacher in China. College English, 47 (8), $789-808$.

[38] Mohan, Bernard.A. \& Lo, Winnie. (1985). Academic writing and Chinese students: Transfer and developmental factors. TESOL Quarterly, 19 (3), 515-34. http://homepage.ntlworld.com/vivianc/SLA/Multicompetence/index.htm.

[40] Odlin, Terence. (1989). Language transfer: Cross-linguistic influence in language learning. Cambridge: Cambridge University Press.

[41] Pavlenko, Aneta. (2000). L2 influence on L1 in late bilingualism. Issues in Applied Linguistics, 11 (2), 175-205.

[42] Pavlenko, Aneta. (2003). "I never knew I was bilingual": Reimagining teacher identities in TESOL. Journal of Language, Identity, and Education, 2(4), 251-268.

[43] Skwire, David. (1979). Writing with a thesis: A rhetoric and reader (2 ${ }^{\text {nd }}$ Ed.). New York: Holt, Rinehart and Winston.

[44] Snively, Helen. (1999). Coming to terms with cultural differences: Chinese graduate Students writing academic English. Unpublished Doctoral Dissertation. Harvard University, Cambridge. 
[45] Su, I-Ru. (2001). Transfer of sentence processing strategies: A Comparison of L2 learners of Chinese and English. Applied Psycholinguistics, 22, 83-112.

[46] Wang, Chuang. (1992). Paragraph organization in English and Chinese academic prose: A Comparative study. Unpublished doctoral dissertation. Indiana University of Pennsylvania.

[47] Weinreich, Ulrich. (1953). Language in contact. The Hague: Mouton.

[48] Wu, Hui. (2009). Lost and found in translation: Modern conceptualization of Chinese rhetoric. Rhetoric Review, 28(2), 148-166.

[49] Yang, Ling \& Cahill, David. (2008). The rhetorical organization of Chinese and American students' essays: A contrastive rhetoric study. International Journal of English Studies, 8(2), 113-132.

[50] You, Xiaoye. (2005). Conflation of rhetorical traditions: The formation of modern Chinese writing instruction. Rhetorical Review, 24 (2), 150-69.

[51] Zareva, Alla. (2010). Multicompetence and L2 users' associative links: Being unlike nativelike. International Journal of Applied Linguistics, 20, 2-22.

[52] Zhang, Jie. (2011). Linguistic, ideological, and cultural issues in Chinese and English argumentative writings. Journal of Language Teaching and Research, 2(1), 73-80.

[53] Zhang, Qing. (1997). Academic writing in English and Chinese: Case study of senior college students. Unpublished doctoral dissertation. Ball state University, Muncie.

Yingqin Liu was granted a doctoral degree in Technical Communication and Rhetoric from Texas Tech University in 2007. She is currently an Assistant Professor in the Department of English and Foreign Languages, Cameron University, Lawton, Oklahoma, U.S. A. Her major research interests are in the theories and practice of intercultural communication and intercultural rhetoric, second language writing, and business communication. She has published research articles in the areas of intercultural communication and rhetoric and second language teaching.

William Carney holds a PhD from Texas Tech University and is Director of Composition at Cameron University in Oklahoma. Professor Carney teaches courses in EFL, Old and Middle English, and technical writing. He has published in a number of peerreviewed journals and edited collections and his research interests include the composition aspects of teaching English as a foreign language, pedagogy, and the history of rhetoric. 